Available online at GSC Online Press Directory

GSC Biological and Pharmaceutical Sciences

e-ISSN: 2581-3250, CODEN (USA): GBPSC2

Journal homepage: https://www.gsconlinepress.com/journals/gscbps

(RESEARCH ARTICLE)

\title{
RT-PCR diagnosis of invasive Candida albicans strain predominant among a private school in Kirkuk City
}

\author{
Tawfeeq Asal Aziz * \\ Northern Technical University/Technical College of Kirkuk Medical Laboratory Technique Department.
}

Publication history: Received on 01 May 2020; revised on 10 May 2020; accepted on 12 May 2020

Article DOI: https://doi.org/10.30574/gscbps.2020.11.2.0121

\begin{abstract}
This work was carried out to investigate the incidence of the invasive Candida albicans fungus in oral swabs collected from a private primary school and to confirm its invasiveness by RT-PCR. Accordingly, the total of (368) students in the age range of (7-12) years from both sexes was orally examined for the incidence of Candida albicans from 0ctober 2019 to March 2020. Wet oral swabs were directly cultured on Sabouraud agar medium, and positive cultures were examined microbiologically. Results of Gram's staining revealed the isolation of the invasive Candida albicans confirmed by the germ tube test. This fungus was significantly $(\mathrm{P}<0.05)$ prevalent in most of the school students, where males were more affected (64.53\%) than female students (35.47\%) across all age groups. Moreover, the molecular analysis of the isolated fungal strains confirmed the invasiveness of the isolates.
\end{abstract}

Keywords: RT-PCR; Molecular diagnosis; Candida albicans; Private school

\section{Introduction}

The discomfort of thrush has been known to occur in people for over 2000 years, where Candida species presented as both commensals and opportunistic pathogens in the oral cavity [1-3]. For decades, it has captivated the clinicians to investigate its pathogenicity and to improvise newer therapeutic regimens based on the updated molecular research [2-4]. On the other hand, Candida albicans fungal strains were found as a commensal in the oral cavity of about (46\%) of one-year-old infants and (39\%) of 1-6-year-old children [5]. The turning of Candida albicans into a pathogen is usually determined by the host immune system where candida infections might range from non-life threatening superficial mucocutaneous disorders to an invasive disseminated disease involving multiple organs [6-8]. In recent years, a remarkable increase in Candidiasis has been observed, as reflected by the increased incidence of Candida albicans infections among children frequently [7\&8]. The probable explanations included changes in the practice of medicine like the introduction of broad-spectrum antibiotics, immunosuppressive agents, and morbid conditions such as diabetes and severe malnutrition in children [9-11]. On the other hand, oral Candidiasis became a significant source of morbidity, as it can cause chronic pain or discomfort upon eating, limiting nutrition intake in children of different ages $[10 \& 11]$.

Therefore, this study was carried out to estimate the prevalence of invasive Candida albicans fungus in oral swabs collected from a private primary school and to confirm the invasiveness of the pathogen by RT-PCR.

\footnotetext{
* Corresponding author: Tawfeeq Asal Aziz drasalaziz@ntu.edu.iq
} 


\section{Material and methods}

\subsection{Children included in the study}

The total of (368) children of Kirkuk private primary school were the subject of this study. Students were living in different districts of Kirkuk city/Iraq and they were recruited for the study according to the criteria cited in [12].

\subsection{Oral sample collection}

Oral samples obtained by swabbing the oral mucosa (palatal mucosa and tongue dorsal) of all patients with sterile swabs. Then, samples were directly cultured on Sabouraud's dextrose agar medium (Himedia/India) supplemented according to the procedure mentioned in [13]. Plates were incubated at $37^{\circ} \mathrm{C}$ for $24-72$ hours.

\subsection{Microbiological tests}

\subsubsection{Gram's Staining}

Single colonies picked with a loop and were stained according to the manufacturing company Kit protocol (Himedia/India). Slides were examined the magnification of (100 X) objective of a light microscope and were photographed.

\subsubsection{Germ tube test:}

This procedure is followed according to [14] for identifying Candida albicans. The isolated, purified strains were incubated in human serum at $37^{\circ} \mathrm{C}$ for 2 hours, and the ability to produce short, slender, tube-like structures (germ tubes) were recorded as a pathogenic strain.

\subsection{Molecular analysis of invasivness}

\subsubsection{Extraction of DNA}

All isolates were subcultured twice on Sabouraud's dextrose agar and were incubated at $37{ }^{\circ} \mathrm{C}$ for $48-72 \mathrm{~h}$ before molecular analysis. Crude DNA extracts were prepared by a simple boiling method according to [15]. A loopful colony was suspended in $(2 \mathrm{ml})$ of Sabouraud's dextrose broth medium and was incubated overnight at $37{ }^{\circ} \mathrm{C}$. One milliliter of this suspension was transferred to a sterile Eppendorf tube, centrifuged at 13,000 rpm for $10 \mathrm{~min}$. A volume of (200 ml) of sterile distilled water was then added to the pellet and boiled at $100{ }^{\circ} \mathrm{C}$ for 15 min. Then, extracted DNA was transferred to a clean tube and stored at $-20^{\circ} \mathrm{C}$ before RT-PCR.

\subsubsection{Identification of the 310 bp genotype by RT-PCR}

Two primer pairs used to span the site of the transposable intron in the 25S rRNA were CA-INT-L (50-ATAAGG GAA GTC GGC AAA ATA CCG TAA-30) and CA-INT-R (50-CCT TGG CTG TGG TTT CGC TAG ATA GTA GAT-30) as described by [15]. Amplification reactions were performed in $50 \mu$ final volume containing $3.5 \mathrm{mM} \mathrm{MgCl2,} 200 \mathrm{lM}$ dNTP mix, $1 \mathrm{U}$ Taq DNA polymerase (Sigma, USA), $100 \mathrm{pmol}$ (each) of the primers and $4 \mu$ l DNA template. Then, the Genotype of the isolates were investigated by restriction endonuclease analysis by HaeIII and MspI (Thermo Scientific/ France), according to Karahan et al. [16]. DNA extracts of Candida albicans isolates were digested with HaeIII and MspI restriction endonucleases along with the extracted DNA of the standard invasive Candida albicans ATCC 10231 (WDCM 00054 Vitroids $^{\mathrm{TM}}$ /Sigma-Aldrich/Germany) and run on RT-PCR (BioRad/USA). The products were characterized by electrophoresis on $2 \%$ agarose gels and visualized in U.V. transilluminator (BioRad/USA) after ethidium bromide staining.

\subsection{Statistical analysis}

Data from the study were analyzed using a T-test of the SPSS program Ver.10 for Windows, where a $P$ value of $<0.05$ was considered indicative of a statistically significant difference.

\section{Results and discussion}

The fungus Candida albicans is a dimorphic, opportunistic pathogen that causes infections in immuno-compromised individuals where the virulence of this organism is a function of a multiplicity of factors working jointly to overwhelm the host defenses $[1,2,3]$. Recent findings showed an increase in the global burden of fungal infection, especially for 
Candida albicans, where the proportion represented by children is mainly unknown $[6,7,11]$. Besides, most of the local studies had neglected the incidence of the pathogenic Candida albicans in the oral cavity of small children $[17,18,19]$.

Accordingly, the total of (368) of school children were included in this study, and the results of the oral examination showed a high prevalence of Candidial infections among many students who volunteered for the inspection and results indicated that about (198) students out of (368) students examined from the particular primary schools had displayed suspected Candidiasis with an incidence rate of (58.37\%) among all ages and in both sexes. The same results were obtained by $[12,18]$, where they declared a percentage of $(52.33 \%$ and $47.3 \%)$ of Candidiasis among preschool and school children in different parts of the world, respectively.

Subsequently, the suspected Candidiasis oral samples were microbiologically analyzed after the cultivation on selective medium for the identification of the fungal strain and the outcomes of the Gram staining of the wet oral samples and germ tube test had revealed the isolation of Gram's positive budding yeast cells that was almost bearing a resemblance to Candida albicans as shown in (Figure 1).

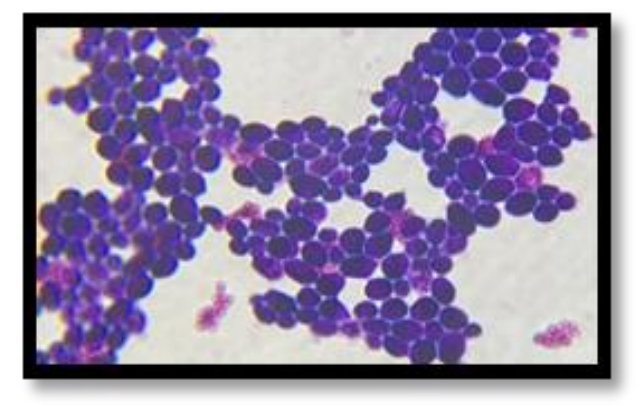

Figure 1 A photograph of light microscope under (100X) magnification showing Gram's positive budding yeast cells of suspected Candida albicans strain isolated from a ten years old male student during the study.

As a consequence, molecular analysis was conducted for the identification of invasive Candida albicans isolates against the genotype sequence of the standard virulent strain of Candida albicans ATCC 10231as described by [19].

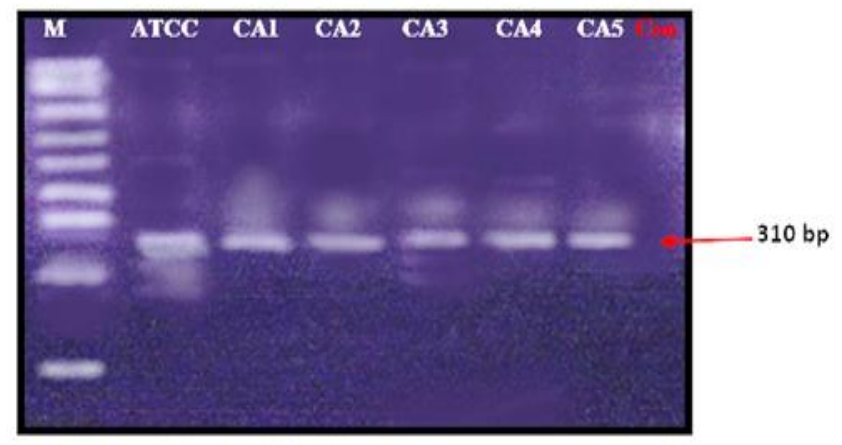

Figure 2 Electrophoretic pattern of RT-PCR amplified DNA products. Lane M, 100-bp marker; Lane 1, C. albicans ATCC 10231 (310 bp): Lanes (CA1-5), the tested C.albicans isolates of the study: Lane Con, negative control, no DNA template (distilled water).

Other Studies $[17,18,20]$ had identified virulent strains of Candida albicans strains at different genotypic base pairs probably because this fungus has significant phenotypic and genetic diversity [20,21]. It contains a diploid genome with 14.4 megabases that are arranged as eight chromosomes [21]. The heterozygosity and heterozygous of the genome are thought to be related to $C$. albicans virulence [24]. Also, it is now well documented that the genomic instability of $C$. albicans plays a significant role in its pathogenesis.

Since the genetic variability of C. albicans can modulate the candida behavior at the host defense mechanism [21]. Thus, the predominance of the invasive strains was analyzed according to the study levels of the infected school children and results were declared in (Table 1) 
Table 1 Distribution of invasive Candida albicans among student in a private primary school.

\begin{tabular}{lllllll}
\hline $\begin{array}{l}\text { Patient's } \\
\text { Gender }\end{array}$ & \multicolumn{7}{l}{ Infected Students Numbers per grades } & & & \\
& 1st & 2nd & 3rd & 4th & 5th & 6th \\
\hline Males & 7 & 10 & 21 & 22 & 26 & 38 \\
Females & 5 & 7 & 11 & 12 & 16 & 20 \\
Total & 12 & 17 & 32 & 34 & 42 & 58 \\
Percentages & $6.15 \%$ & $10.30 \%$ & $16.41 \%$ & $17.44 \%$ & $21.54 \%$ & $29.74 \%$ \\
\hline
\end{tabular}

From the results of the table above, it could be concluded that mouth thrush predominated all ages of students recording a percentage of $(64.53 \%)$ in male students and $(35.47 \%)$ in female students respectively. These results agree with the results obtained previously by $[25,26,27]$, where they exposed that, mouth thrush was very prevalent among preschool and School children due to increased oral cavities due to teeth loss at these ages. However, in this study, it was noticed that the percentage of Candidiasis was significantly higher in males than female students, probably due to poor oral hygiene practices by boys. Moreover, it could be noticed from the table above that the predominance in Candida albicans incidence increased with the age of the students where students of 11-12 years old were more affected by Candidiasis compared to the younger ones probably due to a relationship between personal hygiene with nutrition. The same results obtained by [26, 27], where they concluded that girls had better hygiene practices and eating routines than the boys. Also, the majority of the health problems affecting school children are preventable by the promotion of hygienic practices and healthy eating habits.

\section{Conclusion}

The Maintenance of a healthy mouth environment, a balanced microbial ecology is very crucial to children's health. Besides, invasive Candida albicans was significantly high $(\mathrm{P}<0.05)$ among male students than females of a primary school in 2019. Still, the predominance of invasive Candida albicans increased with student's age.

\section{Compliance with ethical standards}

\section{Acknowledgments}

The present work was carried out at the Medical Laboratory Techniques Department/ Kirkuk / Iraq.

\section{Disclosure of conflict of interest}

The author declares no conflict of interest.

\section{Statement of informed consent}

Informed consent was obtained from all individual participants included in the study.

\section{References}

[1] Höfling JF, Anibal PC, Obando-Pereda GA, Peixoto IA, Furletti VF, Foglio MA and Gonçalves RB. (2010). Antimicrobial potential of some plant extracts against Candida species. Brazilian Journal of Biology. Nov, 70(4), 1065-8.

[2] Owotade FJ and Patel M. (2014). Virulence of oral Candida isolated from HIV-positive women with oral Candidiasis and asymptomatic carriers. Oral surgery, oral medicine, oral pathology and oral radiology, 118(4), 455-60.

[3] Barnett JA. (2008). A history of research on yeasts 12: medical yeasts part 1, Candida albicans. Yeast, 25(6), 385417.

[4] Rautemaa R and Ramage G. (2011). Oral candidosis-clinical challenges of a biofilm disease. Critical reviews in microbiology, 37(4), 328-36. 
[5] Williams D and Lewis M. (2011). Pathogenesis and treatment of oral candidosis. Journal of oral microbiology, 3(1), 5771.

[6] Yilmaz AE, Gorpelioglu C, Sarifakioglu E, Dogan DG, Bilici M and Celik NU. (2011). Prevalence of oral mucosal lesions from birth to two years. Nigerian Journal of Clinical Practice, 14(3), 349-53.

[7] Lund RG, da Silva Nascente P, Etges A, Ribeiro GA, Rosalen PL and Del Pino FA. (2010). Occurrence, isolation and differentiation of Candida spp. and prevalence of variables associated to chronic atrophic Candidiasis. Mycoses, 53(3), 232-8.

[8] Lalla RV, Patton LL and Dongari-Bagtzoglou A. (2013). Oral candidiasis: pathogenesis, clinical presentation, diagnosis and treatment strategies. Journal of the California Dental Association, 41(4), 263-8.

[9] Martins N, Ferreira IC, Barros L, Silva S and Henriques M. (2014). Candidiasis: predisposing factors, prevention, diagnosis and alternative treatment. Mycopathologia, 177(5-6), 223-40.

[10] Tawfeeq AA and Taher SA. (2018). Epidemiological study evaluating the impact of front door duct slot of a combined domestic sewer-rainwater drainage system on children health in Kirkuk, 2017. Karbala International Journal of Modern Science, 4(4), 369-76.

[11] Baddley JW, Benjamin DK, Patel M, Miró J, Athan E, Barsic B, Bouza E, Clara L, Elliott T, Kanafani Z and Klein J. (2008). Candida infective endocarditis. European journal of clinical microbiology \& infectious diseases, 27(7), 519-29.

[12] Tawfeeq AA. (2019). Prospective Cohort Study Defining Candida albicans Infections In Some Primary Schools In South of Kirkuk/Iraq. Proceeding of The 6th International Scientific Conference of Genetic and Environment Baghdad, Iraq, 150-158.

[13] Rozkiewicz D, Daniluk T, Zaremba ML, Cylwik-Rokicka D, Stokowska W, Pawińska M, Dabrowska E, MarczukKolada G and Waszkiel D. (2006). Oral Candida albicans carriage in healthy preschool and school children. Advances in medical sciences, 51, 187-90.

[14] Nassir and Noor Ismaeel. (2010)."Incidence of C. albicans isolates from oral and vaginal candidiasis, study of their susceptibility and cross-resistance to some antifungal agents". Thesis. College of Medicine / Al-Qadisiya University/ Iraq.

[15] Bellemain E, Carlsen T, Brochmann C, Coissac E, Taberlet P and Kauserud H. (2010). ITS as an environmental DNA barcode for fungi: an in silico approach reveals potential PCR biases. BMC microbiology, 10(1), 189.

[16] Karahan ZC and Akar N. (2005). Subtypes of genotype A Candida albicans isolates determined by restriction endonuclease and sequence analyses. Microbiol Res, 160, 361-6.

[17] El-Naggar MY, Al-Basri HM and Karam El-Din AZ. (2010). Molecular diagnosis of Candida albicans using real-time polymerase chain reaction of a CaYST1 gene. Journal of Taibah University for Science, 3(1), 8-13.

[18] Habeeb RA, Al-Saadi AM and Jasim NO. (2015). "Isolation and identification of some types of Candida spp." J. Babylon University/ Pure \&Applied Science, 23(3), 955-964.

[19] Dadar M, Tiwari R, Karthik K, Chakraborty S, Shahali Y and Dhama K. (2018). Candida albicans-Biology, molecular characterization, pathogenicity, and advances in diagnosis and control-An update. Microbial pathogenesis, 117, 128-38.

[20] Yang B and Rao R. (2018). Emerging Pathogens of the Candida Species. InCandida Albicans. Nov 5. IntechOpen.

[21] Ashraf JM. (2010). "Role of Candida albicans Fungi in foundation some protozoa and bacteria". Tikrit Journal of pure science. 15(1), 14-19.

[22] Ali CI, Mahmood AR, Jafar NA and Khorsheed S. (2009). "Prevalence of enteropathogenic diarrhea in Children up to 2 years in Kirkuk province". Tikrit Medical Journal, 15(2), 124-131.

[23] Haydar MA, Al-Hamadani AH and Al-Muhana AM. (2017). "Genotyping and antifungal susceptibility profile of Candida albicans isolated from neonatal thrush infections in Iraq. Al-Qadisiya Medical Journal, 9(15), 240-249.

[24] Hameed AR, Ahmed L and Ali SM. (2018). "The Prevalence of Candida spp. Among Children with Diarrhea in Baqubah-Iraq". International Journal of Advanced Research in Engineering \& Technology, 1(3), 34-43.

[25] Moreira D, Spolidorio DMP, Rodrigues JA de O, Boriollo MFG, Pereira CV, Rosa EAR and Hofling JF. (2001). "Candida spp. biotypes in the oral cavity of school children from different socioeconomic categories in Piracicaba - S.P., Brazil". Pesqui Odontol Bras, 15(3), 187-195. 
[26] Sarkar M. (2013). Personal hygiene among primary school children living in a slum of Kolkata, India. Journal of preventive medicine and hygiene, 54(3), 153.

[27] Deb S, Dutta S, Dasgupta A and Misra R. (2010). Relationship of personal hygiene with nutrition and morbidity profile: A study among primary school children in South Kolkata. Indian journal of community medicine: official publication of Indian Association of Preventive \& Social Medicine, 35(2), 280.

\section{How to cite this article}

Tawfeeq AA. (2020). RT-PCR diagnosis of invasive Candida albicans strain predominant among a private school in Kirkuk City. GSC Biological and Pharmaceutical Sciences, 11(02), 124-129. 